\title{
Nos labirintos do discurso: as sombras saussurianas nos processos dialéticos
}

\author{
Júnia Diniz Focas \\ Professora Doutora da Universidade Federal de Minas Gerais (UFMG), Brasil. \\ junia.diniz@globo.com
}

Resumo: Analisar a subjetividade linguística, entender o falante enquanto ator e construtor de uma realidade mediatizada pela e na linguagem implica também considerar parâmetros de análise que privilegiem uma concepção formal de língua que, ao mesmo tempo, incorpore e defina os limites da interlocução e do discurso. Será dessa perspectiva que situaremos nossa discussão sobre a dialética, cujas marcas nas teorizações do sistema lingüístico são indiretamente reconhecidas por Saussure ao formular o aspecto opositivo do signo linguístico, expresso na noção de valor, o que nos possibilita uma ampliação do signo saussuriano contrapondo-o à concepção filosófica amparada nas formulações das Categorias aristotélicas. Um lugar de (re)construção, simultâneo e, ao mesmo tempo, contraditório, no qual as explicações teóricas, sejam elas ideológicas, sociais ou históricas, encontram seu ponto de instabilidade.

Palavras-chave: Dialética. Discurso. Tópicos. Argumentação.

\begin{abstract}
Analysing linguistic subjectivity, understanding the speaker as actor and constructor of a reality mediated by and in language also implies considering parameters of analysis that privilege a formal conception of language that, at the same time, incorporates and defines the limits of interlocution and speech. It is from this perspective that we will situate our discussion of the Dialectic, whose marks in the theorizations of the linguistic system are indirectly recognized by Saussre when formulating the oppositional aspect of the linguistic sign, expressed in the notion of value. This enable us to amplify the Saussurian sign by contrasting it with the philosophical conception supported by the formulations of the Aristotelian Categories. A locus of (re)construction, simultaneous and the same time contradictory, in which the theoretical explanations, be they ideological, social or historical find their poin of instability.
\end{abstract}

Keywords: Dialectic. Speech. Topics. Argumentation. 
Introdução

Iniciemos com uma afirmação essencialmente dialética: o signo é exatamente aquilo que ele não é (SAUSSURE, 2006, p. 136). Portanto, do ponto de vista de Saussure, o signo é definido por seu valor em relação aos outros signos da língua, inserido em uma estrutura cuja principal característica é a hierarquia e o equilíbrio das unidades no interior do sistema linguístico, equilíbrio esse mantido essencialmente pelo valor diferencial e correlativo de seus elementos. Embora, na teoria, prevaleça a concepção de língua, de sistema, em detrimento da fala, compreendemos que o aspecto opositivo dos signos, em suas relações semióticas, requer uma interpretação mais complexa da análise saussuriana da língua, atualizada como elemento formal de uma distinção que se manifesta por meio da fala. Como Saussure já o esclarece:

[...] historicamente é o ato da fala que vem sempre antes. Como se imaginaria associar uma idéia a uma imagem verbal se não se surpreendesse de início esta associação num ato de fala? [...] Existe, pois, interdependência da língua e da fala; aquela é ao mesmo tempo o instrumento e o produto desta. Tudo isso porém, não impede que sejam duas coisas absolutamente distintas (SAUSSURE, 2006, p. 27).

Semelhante constatação apresenta simetria com o pensamento filosófico de Kant para quem "todo o nosso conhecimento começa com a experiência [...] portanto, nenhum conhecimento em nós precede a experiência, e todo ele começa com ela" (KANT, 1991, p. 25). Dessa perspectiva, a dicotomia saussuriana Língua/Ffala apresenta assim uma estreita convergência com o pensamento filosófico de Kant que preconiza uma forma de conhecimento na qual a experiência antecede o próprio objeto de análise, opondo-se assim à clássica concepção filosófica de que seria o objeto que prevaleceria, antecederia, as explicações científicas de determinado fenômeno. Quanto a isso, o próprio Saussure reconhece: “[...] Bem longe de dizer que o objeto precede o ponto de vista, diríamos que é o ponto de vista que cria o objeto; aliás, nada nos diz de antemão que uma dessas maneiras de considerar o fato em questão seja anterior ou superior às outras" (SAUSSURE, 2006, p. 15).

De acordo com esse princípio, o conhecimento científico se efetiva por um duplo processo: o primeiro diz respeito à matéria do conhecimento, dependente do próprio objeto; já o segundo consiste na forma do conhecimento, dependente do sujeito. A fim de melhor fundamentar esse 
postulado filosófico, Kant distingue o conhecimento a priori, referente ao necessário, ao rigor de princípios científicos, sendo o que define como um juízo analítico, descrito por conceitos. Já o conhecimento a posteriori está interligado à experiência, entendido assim como um juízo sintético. Tais considerações empreendem a formulação inédita de um exame crítico do conceito filosófico de Razão, impondo assim limites à sua própria atividade, ao que é possível ou não quanto à prevalência da razão como fonte fundadora do pensamento. A Crítica da Razão Pura "fornece os princípios do conhecimento a priori. Por isso a razão pura é aquela que contém os princípios para conhecer algo absolutamente a priori" (KANT, 1991, p. 34).

Retomando a teoria saussuriana do signo, podemos compreender melhor a prevalência da Língua sobre a Fala, ou o postulado de uma Linguística da Língua que institui uma forma de conhecimento a priori do sistema linguístico, sem que dele esteja desvinculada a experiência, no caso a Fala. Saussure não apenas descreve o sistema, mas o prioriza como forma de conhecimento que só se pode conceber como um dado da experiência que possibilita a explicação científica da Língua no seu aspecto formal (a priori).

Esse panorama teórico é imprescindível na descrição do sistema linguístico como um conhecimento formal, contudo dele não podemos desvincular o exercício da linguagem, as formas de subjetividade, os atos do discurso que instituem o lugar do sujeito, indiretamente reconhecidos por Saussure: "Cumpre reconhecer, porém, que no domínio do sintagma não há limite categórico entre o fato de língua, testemunho de uso coletivo, e o fato de fala, que depende da liberdade individual" (SAUSSURE, 2006, p. 145).

Assim, analisar a subjetividade linguística, entender o falante enquanto ator e construtor de uma realidade mediatizada pela e na linguagem implica também considerar parâmetros de análise que privilegiem uma concepção formal de língua que, ao mesmo tempo, incorpore e defina os limites da interlocução e do discurso. Um lugar de (re)construção, simultâneo e, ao mesmo tempo, contraditório, no qual as explicações teóricas, sejam elas ideológicas, sociais ou históricas encontram seu ponto de instabilidade. 0 desde sempre da ação linguística marcado pela intervenção do homem, construtor e mediador de sua realidade.

Será dessa perspectiva que situaremos nossa discussão sobre a Dialética, cujas marcas nas teorizações do sistema linguístico são indiretamente reconhecidas por Saussure ao formular o aspecto opositivo do signo 
linguístico, expresso na noção de valor, visto que "[...] quando se diz que os valores correspondem a conceitos, subtende-se que são puramente diferenciais, definidos não positivamente por seu conteúdo, mas negativamente por suas relações com os outros termos do sistema. Sua característica mais exata é ser o que os outros não são" (SAUSSURE, 2006, p. 136), o que nos possibilita uma ampliação do signo saussuriano contrapondo-o à concepção filosófica amparada nas formulações das Categorias aristotélicas.

Debate entre contrários? Processo argumentativo criador da ilusão de um consenso? Confronto intrínseco e necessário ao intercâmbio lingüístico? Eis uma questão controversa, um desafio a que nos propomos empreender para inserir a Dialética no contexto teórico e conceitual do pensamento saussuriano.

\section{Definição de Dialética}

A conceituação de Dialética abrange desde a filosofia clássica nos diálogos platônicos até uma concepção mais moderna, especialmente na Nova Retórica, com Perelman e na Teoria da Ação Comunicativa, com Habermas.

Nesse ponto, podemos desenvolver a conceituação de Dialética que, embora indiretamente enfocada por Saussure, notadamente por meio do eixo saussuriano (sintagmático/paradigmático), encontra suas bases na moderna formalização filosófica entre sociedade e discurso, englobando um processo de interlocução que, concomitantemente, é subjetivo e social, sem, contudo, nos desviarmos da percepção de que é pela Língua que o discurso se manifesta como elemento mediador de uma racionalidade na linguagem. Semelhante postulado é exposto no pensamento de Habermas que expressa uma dialetização do mundo da vida para conceber a moderna concepção de racionalidade que se manifesta via discurso, fator introdutório de uma teoria da argumentação. E é exatamente a utilização comunicativa dos atos de fala que pressupõe uma racionalidade comunicativa, capaz de gerar consenso em uma fala argumentativa, motivadora da unidade do mundo objetivo e da intersubjetividade.

Assim, a expressão da Razão encontra uma estreita relação entre racionalidade e o saber que se explicita de forma proposicional, ou seja, as opiniões podem expor-se explicitamente em forma de enunciados. Nessa 
perspectiva, o que mais interessa é expor a maneira como os sujeitos capazes de linguagem e ação fazem uso do conhecimento. O que o filósofo expressa:

\begin{abstract}
Com o entendimento intuitivo do sentido da argumentação, os proponentes e os oponentes se obrigam reciprocamente, sobretudo, a uma descentralização de suas perspectivas de interpretação. Desta maneira, a antecipação idealizadora de Kant da totalidade do mundo é transferida do mundo objetivo para o mundo social. [...] Porque os participantes da argumentação são orientados pela verdade, o conceito de uma verdade válida absolutamente se reflete, no plano da certificação discursiva da verdade, nas idealizações efetuadas performativamente, que emprestam seu caráter cheio de exigências a essas práticas da argumentação (HABERMAS, 2002, p. 60).
\end{abstract}

Portanto, podemos concluir que se nossa compreensão do mundo é dialética, somos imediatamente conduzidos ao raciocínio de que o discurso é essencialmente dialético, sendo, obviamente, marcado pela subjetividade linguística. A questão da Razão e da Racionalidade constitui o cerne do pensamento filosófico ocidental. No que se refere ao pensamento filosófico, os estudos modernos privilegiam a Razão não apenas como forma de pensamento lógico, mas, principalmente, como estruturação de um pensamento que se constrói na linguagem, nos discursos, nas ações.

Segundo Habermas, a racionalidade de nossas ações está intermediada por um tipo de pressuposições ontológicas que estabelece uma relação dialética de determinado ator com o mundo que o circunda, intermediada pelas pretensões de validez de determinada emissão comunicativa. No âmbito dessa visão, a teoria da Ação Comunicativa é definida por Habermas como uma teoria da sociedade, centrada na racionalidade da ação, referente à forma como os sujeitos capazes de linguagem e de ação fazem uso do conhecimento, esse relacionado à objetividade do mundo e à intersubjetividade do entendimento. No que se refere a esse tema, Habermas estabelece uma distinção entre o sujeito agente e o sujeito socializado, concepção que transfere a racionalidade idealizada para uma racionalidade articulada linguisticamente pelos sujeitos socializados no mundo da vida, externalizando não apenas uma racionalidade, mas também e, sobretudo, uma performatividade. Ao afirmar que "o fórum do discurso racional é estipulado por bons fundamentos que devem ostentar sua arte de convencer" (HABERMAS, 2002, p. 44), situa-a como objeto de um mundo da vida socialmente compartilhado, no qual os interlocutores estabelecem entre si uma ação teleológica que visa a um entendimento mútuo, racionalmente mediatizado. O conceito de ação teleológica, em Habermas, pode ser 
equiparado ao de argumento pragmático em Perelman, já que esse se entende como caracterizando o utilitarismo e também o pragmatismo, visto que a realização de um fim ilocucionário pressupõe uma ação teleológica na qual estão cumpridas as necessidades do interlocutor de intervir eficazmente no mundo.

Já a Retórica pode ser então entendida como uma argumentação como processo. Ao passo que a Dialética desenvolve procedimentos pragmáticos da argumentação, formalizados como estruturas distintas da argumentação. No que diz respeito à argumentação como processo, essa relaciona-se ao conceito de auditório universal, conceito compreendido por Perelman como sendo abstrato, sem uma referência empírica, na qual fatos designam apenas objetos de acordo precisos e limitados, ao passo que verdade "apóia-se nos sistemas de alcance mais geral”. Fatos e verdades aparecem fundidos em uma relação recíproca na qual "o enunciado de um fato seja uma verdade e que toda verdade enuncie um fato" (PERELMAN, 2002, p. 77).

O que se pretende demonstrar aqui é a relação entre fato e verdade como elementos de uma realidade do mundo que se estabelece face aos pressupostos de um mundo objetivo e de outro que se fundamenta como uma dimensão na qual os interlocutores interagem racionalmente em uma ação de interlocução que se reflete na linguagem como a totalidade dos fatos, ou seja, como a realização de bons fundamentos, de argumentos. De acordo com esse ponto de vista, os enunciados, dependendo do sistema de crenças em que estão inseridos, e dos valores que comportam, podem ser tratados como fatos ou verdades.

Segundo Habermas, não se é possível uma certificação da verdade, mas sim uma aceitabilidade racional. O que implica que as evidências ou argumentos nunca são totalmente relativos à verdade, mas passíveis de nos convencer de afirmações problemáticas, enquanto elementos de uma fundamentação dialética não como algo já pré-estabelecido por uma razão mediada pelos objetos e por sua respectiva referência, mas sim como a relativização de sentidos que se concretizam na e pela linguagem e de sua relação com o mundo da vida.

Mas de que maneira poderíamos interpretar uma categoria discursiva? Só vislumbro um caminho: o das Categorias de Aristóteles, fundamentadoras da racionalidade do pensamento. 


\section{As Categorias e a argumentação}

Lidar com a conceituação das Categorias de Aristóteles requer uma perspectiva de análise mais acurada, visto que apresenta um intrincado raciocínio lógico, consistindo então em uma forma de ordenação do pensamento e, evidentemente, em elemento orientador do discurso argumentativo, estando a Retórica e a Dialética revestidas de maior complexidade. Aristóteles estabelece um meio termo entre Retórica e Dialética, a elas interpondo as Categorias como elemento mediador de uma lógica discursiva na qual os raciocínios partem não apenas de argumentos, mas de lugares (os topói), entendidos como a articulação do pensamento com a lógica de um raciocínio onde estão inerentes elementos que são indissociáveis em sua estruturação. Posteriormente, Kant denomina as Categorias de Juízos, mas retoma a denominação original de Aristóteles, visto que somente elas são capazes de estruturar o raciocínio discursivo.

Considerar as Categorias como elementos delimitadores da Retórica e da Dialética é percorrer um labirinto no qual esses elementos do discurso seriam caracterizados por percursos distintos, embora, paradoxalmente, bastante semelhantes, o que torna a argumentação mais dinâmica no que se refere às construções de uma discursividade na qual a marca da intersubjetividade não é mais fruto apenas da linguagem, mas também da complexidade dos raciocínios lógicos nas relações intersubjetivas.

Semelhante pensamento constitui, dentre outros, uma das principais bases do pensamento filosófico de Habermas, principalmente no que se refere à teoria da Ação Comunicativa, na qual a intersubjetividade se processa via um consenso discursivamente mediatizado no âmbito da Razão, de uma racionalidade construída pelos interlocutores, implícita no próprio intercâmbio linguístico, depreendida pela relação língua/linguagem. Serão exatamente esses elementos fundamentadores da primazia da lógica que as Categorias representam ao nos fornecer subsídios para compreender mais profundamente o mecanismo de nossas representações linguísticas.

Uma primeira observação a respeito das Categorias é a de que elas, ao marcar o lugar do discurso, marcam também a estruturação de um raciocínio que define a origem do argumento de um ponto de vista subjetivo e argumentativamente marcado. Definição (essência), propriedade (peculiaridade), gênero (inerência, espécie) e acidente (transitoriedade) são marcas que determinam ou pressupõem uma relação dialética que podemos 
$\mathrm{EI} \square \mathrm{dA}$

Revista Eletrônica de Estudos Integrados em Discurso e Argumentação, Ilhéus, n. 17, jul./dez. 2018.

depreender no interior dos sistemas linguísticos, daí se inferindo a discursividade da linguagem. Essa relação dialética fundamenta todo o pensamento de Saussure, mais especificamente no eixo paradigmático e sintagmático e na definição de signo: o signo é exatamente aquilo que ele não é. A esse respeito, Mounin opera a seguinte interpretação a respeito do signo linguístico:

Para Saussure, o sentido de uma palavra fica na estreita dependência da existência ou da inexistência de todas as outras palavras que têm ou podem ter relação com a realidade designada por essa palavra: o sentido da palavra temer é delimitado pela existência de outras palavras como recear, ter medo, etc...cujo conjunto forma, não um inventário por adição, mas sim um sistema, isto é, uma espécie de rede cujas malhas semânticas são todas interdependentes (MOUNIN, 1965, p. 33).

O argumento então passa a ser compreendido não apenas como uma possibilidade retórica, ultrapassando assim os seus próprios limites no que se refere a produzir um efeito, convencer, persuadir, etc. O raciocínio assume aí uma importância inquestionável, já que definir algo implica obrigatoriamente, além de explicitar uma essência, distinguir suas propriedades, seus gêneros e seus acidentes. Clareando essas explanações, podemos admitir, como exemplo, a palavra homem, definido, por um acordo tácito entre interlocutores, como sendo humano, racional, etc. No entanto, apenas essa definição é insuficiente, pois o ser homem presume não apenas essa definição, mas um complexo de relações que o especificam como bondoso, perverso, etc. (propriedade); ser dotado de inteligência (gênero); e, obviamente aspectos circunstanciais, como exemplifica o próprio Aristóteles, o fato de estar sentado ou em pé (acidente). Dito de outra forma, as categorias constituem o núcleo do processo argumentativo, se concluirmos que argumentar é partir de lugares que privilegiem uma determinada interpretação ou intenção. Perelmam (2002) também reconhece essa estrutura mais profunda nas argumentações lógicas quando elabora o conceito de valor, mais especificamente centralizado nos conceitos de quantidade e qualidade, como também ao caracterizar o auditório universal e particular.

Assim, as Categorias, além de serem categorias de pensamento, estruturam e condicionam a própria Língua, estando nela inscritas como uma forma de expressar o pensamento cultural e socialmente marcado na e pela linguagem. Sobre isso Benveniste assinala: 
Na medida em que as categorias de Aristóteles se reconhecem válidas para o pensamento, revelam-se como a transposição das categorias de língua. É o que se pode "dizer" que delimita e organiza o que se pode pensar. A língua fornece a configuração fundamental das propriedades reconhecidas nas coisas pelo espírito. Essa tábua dos predicados informa-nos, pois, antes de tudo, sobre a estrutura das classes de uma língua particular” (BENVENISTE, 1976, p. 76).

As Categorias, portanto, traduzem tipos de argumentação que se processam por intermédio de um lugar que privilegia uma determinada posição enunciativa e subjetiva, sendo o espaço da relativização das idéias, já em si fluídas, mas ao mesmo tempo revestidas de materialidades que se refletem e se resolvem no próprio discurso ao confrontar identidades e diferenças intrínsecas às formas linguísticas, articulando uma semântica do sentido unicamente possível via uma relação de oposição e contradição, tal como o preconizou Saussure.

Associar as Categorias à argumentação significa considerar a discursividade por um outro ângulo de visão, visto que seus elementos intermediadores não são apenas categorias do Discurso, mas sim formas de raciocínio lógico que delimitam as fronteiras entre a linguagem e seus aspectos lógico-filosóficos. Uma primeira observação diz respeito à articulação de um raciocínio argumentativo, especificamente semelhante aos processos argumentativos definidos ou especulados pela Linguística.

De que forma, então, poderemos efetuar essa convergência com uma concepção puramente linguística? Se observamos as Categorias, a elas acrescentando algumas considerações de Kant a esse respeito, poderemos depreender a sua natureza e seu processo inicial.

Não podemos pensar objeto algum senão mediante categorias: não podemos conhecer objeto pensado algum senão mediante intuições correspondentes àqueles conceitos. Ora, todas as nossas intuições são sensíveis, e tal conhecimento na medida em que seu objeto é dado, é empírico. Conhecimento empírico, porém, é experiência. Conseqüentemente, não nos é possível nenhum conhecimento a priori senão unicamente com respeito a objetos de experiência possível [...] as categorias contêm, por parte de entendimento, os fundamentos da possibilidade de toda experiência em geral (KANT, 1991, p. 94-95).

Para nós, portanto, argumentar pressupõe necessariamente um enfoque no que Kant define como uma experiência, não entendida em seu sentido mais imediato. Experiência é parte de uma concepção filosófica que intermedia a distinção entre entendimento e conhecimento, sendo que não há nenhuma outra maneira de conhecer a não ser por conceitos e, previsivelmente, "o entendimento em geral pode ser representado como uma "faculdade de 
julgar" (KANT, 1991 p. 64). E, assim, só podemos julgar através de conceitos, esses relativos às categorias aristotélicas. Logo, argumentação, para nós está interligada à faculdade de julgar, ou de estabelecer um juízo mediante a postulação de conceitos que se expressam via categorias. Nisso consiste a inserção da Dialética como parte de uma argumentação.

Quanto a essa questão, é importante esclarecer que definir ou explicar a Dialética significa levar em consideração dois aspectos primordiais: o primeiro que advém de uma interpretação clássica de dialética, debate entre interlocutores, não visando à verdade, mas sim à plausibilidade de uma argumentação que se processa como um raciocínio baseado em premissas não necessariamente lógicas, mas aceitáveis como ponto de partida da argumentação, o que a diferencia, em certo aspecto, da Retórica que visa a surtir um efeito, convencer, persuadir. Dialética, nesse sentido, consiste em uma forma da racionalidade estruturada na discussão entre fatos opostos ou contraditórios. O segundo aspecto diz respeito também à racionalidade, mas a Dialética moderna compreende postulados distintos da clássica, principalmente porque a oposição ou contradição não são mais elementos primordiais, prevalecendo a idéia de argumentação na qual se tem uma tese e uma antítese, delas derivando uma síntese, consistindo, portanto, em um diálogo crítico. Sobre isso Perelman nos diz:

No diálogo crítico põe-se à prova uma tese do interlocutor ou uma hipótese que a própria pessoa pode sustentar, para ver se ela não é incompatível com outras teses asseguradas. O raciocínio dialético, em Aristóteles, é aquele cujas hipóteses iniciais são racionais, ou seja, aceitas pelo senso comum, pela grande maioria dos homens ou pelo menos pelos mais sensatos dentre eles (PERELMAN, 1999, p. 7).

Portanto, entenderemos aqui Dialética como um diálogo crítico e a distinguiremos da Retórica, que se baseia na verossimilhança, reivindicando para aquela a marca distintiva das categorias aristotélicas definidoras do conhecimento que se processa via conceitos, ou seja, as categorias ou lugares que delimitam as argumentações no discurso.

Diálogo crítico, portanto, implica a presença de enunciadores que se posicionam em uma relação discursiva, por assim dizer, polêmica. Serão, portanto, enunciadores polêmicos no sentido de que os argumentos do discurso revestem-se de uma característica na qual os raciocínios que os embasam estão circunscritos às relações lógicas das categorias. Parte-se de argumentos conceituais, embasados na relatividade dos conceitos 
polemizados, relatividade essa validada pela categorização dos argumentos nos raciocínios argumentativos.

Assim, um interlocutor, ao expor uma posição fundamental, estipula discursivamente aquilo que reconhece como plausível, estabelecendo, assim, a possibilidade de interpelação, não pelo diálogo ou argumento em si, mas pela racionalidade, pela plausibilidade do argumento enquanto lugar categoricamente marcado no próprio discurso, explicitado abaixo:

Por que considerar "excluídos" aqueles que nunca estiveram de fato "incluídos"?

Ao formular essa indagação, Ferreira Gullar, discute a definição do termo excluído face ao seu oposto incluído, exposta no seguinte fragmento de texto:

De algum tempo para cá, a parte da sociedade que mora em favelas e bairros pobres é qualificada como "excluída". Ou seja, os moradores da Rocinha e do Vidigal, por exemplo, não vivem ali porque não dispõem de recursos para morar em Ipanema ou Leblon, e sim porque foram excluídos da comunidade dos ricos. E eu, com minha mania de fazer perguntas desagradáveis, indago: mas alguma vez aquele pessoal da Rocinha morou nos bairros de classe média alta e dos milionários? Afora um ou outro que possa ter se arruinado socialmente ou que tenha optado por residir ali, todos os demais foram levados a isso por sua condição econômica ou porque ali nasceram. Então por que considerá-los "excluídos", se nunca estiveram "incluídos"? No meu pouco entendimento, excluído é quem pertenceu a uma entidade ou a comunidade e dela foi expulso ou impedido de nela continuar. Quem nunca pertenceu às classes remediadas ou abastadas não pode ter sido excluído delas. Mais apropriado seria dizer que nunca foi incluído. Ainda assim, se não me equivoco, incorreríamos em erro" (GULLAR, 2007).

A argumentação de Ferreira Gullar gira em torno exatamente da questão do que seja, dialeticamente, entendido como inclusão/exclusão, em outros termos, se podemos interpretá-los como uma definição ou como o gênero que se predica aos indivíduos marginalizados socialmente.

Analisando sob o ponto de vista da dialética aristotélica, excluído, nesse texto, é categorizado no sentido de marginalizado, como uma definição, a essência de exclusão. No entanto, a argumentação de Ferreira Gullar baseia-se exatamente na categorização de excluído como seu próprio gênero, ou seja, não incluído, já que a noção de não pertença não comporta a de exclusão, mas sim a de marginalização.

A discussão equivale, portanto, ao questionamento de um discurso social que se valida ou se legitima na manipulação discursiva entre incluído/ excluído/ e no qual excluído não comporta, na negação, não incluído. A esse 
respeito, Aristóteles (1991, p.25) afirmava que “devemos também definir os erros que ocorrem nos problemas. São eles de duas espécies, causados ou por um juízo falso, ou por uma transgressão da linguagem corrente." Tal opinião é ainda corroborada na seguinte passagem: "Supondo-se, por exemplo, que o "correto" signifique "o conveniente" ou “o honroso", procurar-se-á estabelecer ou rebater ambas as descrições do sujeito em questão, mostrando, por exemplo, que ele é honroso e conveniente, ou que nem é honroso, nem conveniente" (ARISTÓTELES, 1991, p. 28).

Fato semelhante é colocado em causa por Ferreira Gullar, visto que os sentidos articulados encontram-se problematizados não pelo sentido em si, mas por um ângulo discursivo no qual a constituição do discurso engendra-se nos processos de enunciação que categorizam os sentidos e o próprio discurso.

Saussure expressa pensamento semelhante ao estabelecer a seguinte comparação ou paralelismo:

Assim, se a idéia positiva de suplício fosse a verdadeira base da idéia de suplício, seria, portanto, impossível falar, por exemplo, "do suplício de usar luvas muito apertadas", que não tem a menor relação com os horrores da grelha e da roda. Dir-se-á: mas isso é próprio, justamente, da locucão figurada." [...] Vemos, então, que não é a idéia POSITIVA contida em suplício e martírio, mas o fato NEGATIVO de sua oposição, que estabelece toda a série de seus empregos, permitindo qualquer emprego, contanto que não invada o domínio vizinho. (Seria preciso, naturalmente, considerar, além disso, tormento, tortura, aflição, agonia, etc.) (SAUSSURE, 2002, p.73, grifos do autor).

A questão não é por si só suficiente para estabelecermos uma predicação possível, mas sim de conceber as suas diversas possibilidades na lógica de uma argumentação. Assim sendo, exclusão/inclusão estão definidos no discurso, no ângulo do que se deseja estabelecer para defender um ponto de vista, por uma subjetividade, por uma enunciação.

Benveniste fornece-nos uma descrição linguística da categoria, mas, essencialmente, o que pretende com isso é estabelecer a idéia de que elas constituem um fenômeno de linguagem e, neste particular, atribui-Ihes um valor linguístico:

Ser-nos-á permitido considerar essas categorias sem preocupação de tecnicidade filosófica, simplesmente como o inventário das propriedades que um pensador grego julgava predicáveis a um objeto, e consequentemente como a lista de conceitos a priori que, segundo ele, organizavam a experiência (BENVENISTE, 1976, p. 70-71). 
A análise das categorias, efetuadas por Benveniste, aponta, além da caracterização morfológica e gramatical, para certas propriedades que as situam como expressões linguísticas e não apenas como meras categorias lógicas.

É exatamente essa possibilidade semântica de mudança e instabilidade do termo na proposição que caracteriza a nossa reivindicação da natureza lingüística da Categoria aristotélica. Daí a necessidade de se verificar as semelhanças e diferenças entre os vários significados, a fim de confirmar se são espécies do mesmo gênero, não havendo, portanto, diferenças de significado no emprego da palavra.

A sutileza dessa distinção é especificada por Aristóteles ao separar espécie e nome sendo aquela relativa a uma categorização, gênero e esta relativa à ausência da categorização, funcionando como um tipo de qualificação, uma especificação metafórica do termo que mantém inalterados seus traços originais, distinguindo diferentes processos de referência ou de representação linguística. Categoria como a de gênero determina a articulação de uma lógica discursiva na qual a idéia de espécie delimita um ponto de partida no qual a relação de um termo ou de uma predicação, no contexto de uma proposição, só pode ser compreendida se a associarmos à espécie.

Contudo, não é essa determinação semântica que nos interessa de imediato, embora seja ela altamente relevante, devemos nos deter nos aspectos argumentativos das Categorias, analisando de que maneira elas podem contribuir para explicitar a estruturação dos processos argumentativos e dos raciocínios que implicam.

\section{Considerações Finais}

Aqui, podemos agora delimitar mais precisamente a fronteira entre a Dialética e a Retórica, visto que são mecanismos argumentativos que se complementam embora possuam aspectos discursivos um pouco distintos. Novamente, retomo Aristóteles ao reconhecer que:

[...] atendendo a que a demonstração da Retórica é o entimema; que este fornece, em resumo, a convicção mais decisiva; assente que o entimema é uma espécie de silogismo e que a Dialética, tomada em conjunto ou numa de suas partes, tem por missão tratar indiferentemente de toda sorte de silogismos, resulta que todo aquele que melhor souber aprofundar as premissas e a marcha do silogismo, será, por isso mesmo, mais apto para manejar o entimema, desde que possua igualmente conhecimento dos objetos a que os entimemas se referem e das diferenças que os distinguem dos silogismos lógicos. Com efeito, a distinção do verdadeiro e do verossímil depende da mesma faculdade (ARISTÓTELES, 2005, p. 30). 
Quanto a isso, atente-se que há uma sutil diferença entre entimema e silogismo, sendo que o que marca decisivamente a tênue fronteira entre eles é exatamente o fato de que é o silogismo lógico que delineia a distinção, no discurso, entre o que hoje podemos definir como um argumento plausível (dialético) e outro que se pauta pela verossimilhança (retórico), marcado pelos entimemas, mas, ao mesmo tempo, fundamentados categoricamente pelos silogismos lógicos, o argumento dialético.

A questão da Razão e da Racionalidade constitui o cerne do pensamento filosófico ocidental. No que se refere ao pensamento filosófico, os estudos modernos privilegiam a Razão não apenas como forma de pensamento lógico, mas, principalmente, como estruturação de um pensamento que se constrói na linguagem, nos discursos, nas ações.

Nesse mesmo pensamento encontra-se Habermas, ao afirmar:

Toda ciência que admite as objetivações de significado como parte de seu domínio de objetos tem que se ocupar das conseqüências metodológicas do papel de participante assumido pelo intérprete, que não "dá" significados às coisas observadas, mas que tem, sim, que explicitar o significado "dado" de observações que só podem ser compreendidas a partir de processos de comunicação (HABERMAS, 1989, p. 44).

Assim, ao discutir as nuances argumentativas entre incluído/excluído, Gullar deixa a impressão de que essa questão encontra-se em aberto, sendo compreendida no conjunto das práticas sociais, ou seja, quais mecanismos argumentativos referendam os termos exclusão/inclusão em uma determinada categoria de sentido ou de discurso?

Finalmente retomamos Saussure:

Da mesma maneira, quando um filósofo ou um psicólogo, depois de suas meditações, por exemplo, sobre o jogo de nossas faculdades, entra em cena com um sistema que faz tabula rasa de qualquer noção anterior, mesmo assim todas as suas idéias novas, por mais revolucionárias que sejam, podem se classificar sob os termos da língua corrente, mas, em todo caso, nenhuma pode se classificar indiferentemente sob as palavras existentes, mesmo que sejam perfeitamente arbitrárias, como razão ou intelecto, inteligência ou entendimento, julgamento, conhecimento, etc; e que haja aí DE ANTEMÃO um determinado termo que corresponda melhor do que os outros às novas distinções" (SAUSSURE, 2002, p.72, grifos do autor).

Portanto, o que caracteriza filosoficamente o pensamento aristotélico é a dimensão de uma Razão entendida como uma demonstração baseada em silogismos que são, por assim dizer, categorizações que exprimem a essência das coisas e do mundo. A questão em relação a essas exposições é a do papel 
$\mathrm{EI} \sqcap \mathrm{dA}$

Revista Eletrônica de Estudos Integrados em Discurso e Argumentação, Ilhéus, n. 17, jul./dez. 2018

desempenhado pela dialética, focalizada na semântica da linguagem, na pertinência das argumentações (os topói) que validam a relação do termo com as suas diferenças de sentido, consistindo, portanto, no método dialético que, indiretamente, também é preconizado por Saussure. O eterno conflito entre argumentos e discursos. Labirintos da linguagem cujas sombras se projetam na multiplicidade de vozes que desvelam os significados e seus sentidos.

\section{Referências}

ARISTÓTELES. Tópicos. Dos argumentos sofísticos. São Paulo: Nova Cultural, 1991. (Coleção Os Pensadores)

. Arte Retórica e Arte Poética. Tradução: Antonio Pinto de Carvalho. 17. ed. Rio de Janeiro, Ediouro, 2005 [386 a.C.].

BENVENISTE, Émile. Categorias do pensamento e categorias de língua. In: Problemas de Linguística Geral. São Paulo: Cultrix, 1976. p. 68-94.

GULLAR, Ferreira. Exclusão social, o que é isso? São Paulo: Folha de São Paulo, 2007.

HABERMAS, Jürgen. Agir comunicativo e razão descentralizada. Rio de Janeiro: Tempo Brasileiro, 2002.

- Ciências sociais reconstrutivas versus ciências socais compreensivas. In: . Consciência Moral e Agir Comunicativo. Rio de Janeiro, Tempo Brasileiro, 1989. p. 37-60.

. Sobre o uso pragmático, ético e moral da razão prática. In: A ética do Discurso. Lisboa: Edições 70, 2014. p. 319-337.

KANT, Immanuel. Crítica da Razão Pura. São Paulo: Nova Cultural, 1991.

MOUNIN, George. Atividades da tradução à luz das teorias sobre a significação em linguística. In: . Os problemas teóricos da tradução. São Paulo: Cultrix, 1965. p. 31-62.

PERELMAN, Chaïm. Dialética e Diálogo. In: . Retóricas. São Paulo: Martins Fontes, 1999. p. 3-10.

PERELMAN, Chaïm; OLBRECHTS-TYTECA, Lucie. Os âmbitos da argumentação. In: Tratado da Argumentação. São Paulo, Martins Fontes, 2002. p. 15-66.

SAUSSURE, Ferdinand. Curso de Linguística Geral. 27. ed. Tradução: Antônio Chelini, José Paulo Paes e Izidoro Blikstein São Paulo: Cultrix, 2006. 
$\mathrm{EI} D \bar{\alpha} \mathrm{A}$

Revista Eletrônica de Estudos Integrados em Discurso e Argumentação, Ilhéus, n. 17, jul./dez. 2018

. Sobre a essência dupla da Linguagem. In: Escritos de Linguística

Geral. São Paulo: Cultrix, 2002. p. 71-80.

\section{Forma de citação sugerida}

FOCAS, Júnia Diniz. Nos labirintos do discurso: as sombras saussurianas nos processos dialéticos. EID\&A - Revista Eletrônica de Estudos Integrados em Discurso e Argumentação, llhéus, n. 17, p. 69-84, jul./dez.2018. DOI dx.doi.org/10.17648/eidea-17-1804. 